\title{
Differentiating between Good Readers and Poor Readers: The Role of Linguistic and Cognitive Factors
}

\author{
H. Memisevic, A. Dedic, and D. Malec
}

\section{ABSTRACT}

Attainment of reading ability is one of the most important goals of early elementary education. The goal of the present study was to compare groups of good readers and poor readers on several cognitive and linguistic skills and to determine the influence of these variables in differentiating these two groups of readers. An additional goal was to determine whether there are differences in proportion of boys and girls in groups of good and poor readers. The sample for this study comprised 60 third-grade children divided in two categories, 30 children in the category of good readers and 30 children in the category of poor readers. The results of this study revealed the largest differences between good readers and poor readers were on the phoneme deletion task and processing speed task. Another finding is that more boys than girls were in the group of good readers and more girls than boys in the group of poor readers. It is very important to know which underlying skills best differentiate good and poor readers at certain age. This in turn will lead to creating more effective reading interventions.

Keywords: Cognitive Factors, Gender Differences, Linguistic Factors Reading Abilities

\section{INTRODUCTION}

Attainment of reading ability is one of the main goals in the first grades of elementary school (Biščević et al., 2021). According to the simple view of reading, reading is composed of decoding and linguistic comprehension (Hoover \& Gough, 1990). These two skills, decoding, and linguistic comprehension, are both necessary prerequisites for reading comprehension. However, relative contribution of these skills to reading comprehension is still a contentious issue. Decoding is part of reading fluency which itself is a complex process. Research on reading fluency has soared in the last couple of decades (Crosson \& Lesaux, 2010; Hasbrouck \& Tindal, 2006; Morris et al., 2018; Park \& Kim, 2015). To be able to read fluently, one needs to have sufficient accuracy for decoding words, to have adequate speed of reading and to have adequate prosody or expression. Defined in such a broad way, reading fluency is a very good indicator of overall reading development (Fuchs et al., 2001; Zumeta et al., 2012) and has been marked as a bridge from decoding to reading comprehension (Pikulski \& Chard, 2005). Numerous studies have examined the predictors of reading fluency in different languages and with different orthographic depth (Georgiou et al., 2008; Landerl et al., 2019; Memisevic et al., 2019; Tobia \& Marzocchi, 2014). Most studies have found that phonological awareness and rapid automatized naming (RAN) have a large effect on reading fluency. Research in reading disabilities has shown that children with reading disabilities usually have some deficits in phonological processing. However, not all
Published Online: January 13, 2022

ISSN: $2736-4534$

DOI : 10.24018/ejedu.2022.3.1.235

\section{H. Memisevic*}

Faculty of Educational Sciences,

University of Sarajevo

(e-mail: hmemisevic@ gmail.com)

A. Dedic

Faculty of Educational Sciences,

University of Sarajevo

(e-mail: admira2601@ gmail.com)

D. Malec

Faculty of Educational Sciences,

University of Sarajevo

(e-mail: demallecci@gmail.com)

*Corresponding Author children with reading disabilities have phonological processing deficits. Research with hyperlexic children (Grigorenko et al., 2003) has shown that children can have excellent decoding skills but still have problems with understanding (Ostrolenk et al., 2017). In fact, according to the simple view of reading, children can have reading deficits due to both fluency deficits and comprehension deficits, to fluency deficits only and due to comprehension deficits only.

Reading disabilities are prevalent in elementary school children. Some studies have shown that the prevalence of reading delay in elementary school students is around $12 \%$ (Fluss et al., 2008). Reading delays can originate from many reasons such as poor phonological skills (Carroll \& Snowling, 2004), deficits in RAN (Powell et al., 2007), poor processing skills (Hoskyn \& Swanson, 2000), and working memory deficits (Cain et al., 2004). Besides linguistic and cognitive factors, deficits in perceptual abilities can also lead to reading difficulties (Zoccolotti et al., 2016). In addition to these, some psychological variables such as motivation can play a significant role in reading (Troyer $e t$ al., 2019). Finally, demographic variables such as gender (Daly \& Corcoran, 2019) and socio-economic status (Romeo et al., 2017) have an effect on reading development. In this regard, favorable socio-economic status has been linked to better reading outcomes, while the studies regarding gender have found female advantage in reading (Breda \& Napp, 2019). The reading advantage for girls seems to increase with schooling, with difference being small in earlier grades and increasing with higher grades 
(Reilly et al., 2019). Other factors, besides gender, have a varying level of importance in reading in different grades. Knowing the factors contributing to reading success and reading failure at different ages and different grades would inform the practice and would help the teachers and reading specialists to create more effective reading interventions.

This study is part of the larger study examining predictors of reading fluency and reading comprehension in Bosnian (Memisevic et al., 2020). Bosnian language is a language with a transparent orthography and children are expected to be able to gain information from the text they read by the third grade. The literature on differentiating good and poor readers is scarce in languages with transparent orthographies.

Thus, in this study we set to answer the following questions:

1. Are there differences in the proportion of boys and girls belonging to the categories of good readers and poor readers at Grade 3?

2. What are the greatest differences in several linguistic and cognitive skills between good readers and poor readers at Grade 3?

3. How efficient these different linguistic and cognitive skills are at differentiating good and poor readers?

\section{Methodology}

\section{A. Participants}

The sample for this study composed of 60 children (27 boys and 33 girls; mean age: 8.5 years, SD- 0.6 years) attending third grades of elementary school. These 60 children are a subset of a sample consisting of 168 children used in a previous study examining the predictors of reading speed and reading comprehension in Bosnian (Memisevic et al., 2020). Children were recruited from four randomly chosen elementary schools in Canton Sarajevo (three urban and one suburban school). According to children's educational records, all children were free of any developmental disability or other neurological condition and none of them received any special education support.

\section{B. Procedure}

Detailed procedure and measures were described in Memisevic et al. (2020). Here we will only briefly mention the tests used.

\section{Reading speed}

Children were asked to read aloud a short, previously unseen text and the time to finish the reading was used as a measure of reading speed.

\section{Reading comprehension}

This task required children to answer a set of literal questions regarding the text that students have just read.

These two tasks served to create a total Reading score which was calculated as the number of correct answers on reading comprehension test divided by reading passage time (shown below).

$$
\text { Reading score }=\frac{\text { Reading comprehension }}{\text { Reading speed }}
$$

The first 30 ranked children (18\% of the sample) were arbitrarily classified as good readers and last 30 ranked ( $18 \%$ of the sample) children were arbitrarily classified as poor readers and these 60 children were selected for subsequent analysis.

\section{Linguistic and Cognitive Factors}

\section{Rhyme detection task}

This task was presented in a picture format. Students were presented with a list of 16 objects and told that each picture has a rhyme pair. Children were first named all the objects in the picture by the examiner to avoid any ambiguity in naming objects. Faster times mean better performance.

\section{Phoneme deletion task}

In this task, children were shown a list of 16 objects and were asked to name the objects without the first sound. Three demonstration items were given prior to the task. Again, faster times mean better performance.

\section{Rapid automatized naming Letters (RAN: Letters)}

This task comprises of five lowercase letters (a, d, o, p, s) that randomly repeat 10 times in an array of five rows for a total of 50 stimulus items (Wolf \& Denckla, 2005). Time to name all the items was used as a measure of RAN letters.

\section{Rapid automatized naming Objects (RAN: Objects)}

This task comprises of five stimulus items (hand, book, dog, star, and chair) that randomly repeat 10 times in an array of five rows for a total of 50 stimulus items (Wolf \& Denckla, 2005). Time to name all the items was used as a measure of RAN: Objects.

\section{Processing speed}

As a measure of processing speed, we used computerized version of letter-digit symbol substitution test from Psychological Experiment Building Language (Mueller \& Piper, 2014). In this task, nine letters and nine digits are paired at the top of the screen. Children are requested to press the digits on the keyboard corresponding to letters presented in a random order. The task consists of 30 trials and takes approximately 3 min to finish. Time was measured in milliseconds and faster times mean better performance.

\section{Working memory}

As a measure of working memory, we used a computerized version of Corsi backward test (Mueller \& Piper, 2014). The computerized version of this test was made on the basis of test description given by Kessels et al. (Kessels et al., 2000). Children were asked to mimic the researcher (in reverse order) as we tapped a sequence of nine identical spatially separated blocks. Higher scores mean better performance.

\section{Semantic fluency}

Semantic category of animals was used in this test. We used a standard procedure for conducting this test (Troyer et al., 1997). In this task, we asked children to name as many animals as possible in $1 \mathrm{~min}$. Total number of named, nonrepeated animals was used as a measure of semantic fluency. Again, higher scores mean better performance. 


\section{Statistical Analysis}

To determine whether there are differences in the proportion of boys and girls in good readers and poor readers we performed a Fisher exact test. In order to

TABLE I: NUMBER OF BOYS AND GIRLS IN THE GROUPS OF GOOD READERS AND POOR READERS

\begin{tabular}{ccccc}
\multicolumn{3}{c}{ GOOD READERS AND POOR READERS } \\
\hline \hline \multirow{2}{*}{ Gender } & \multicolumn{2}{c}{ Good Readers } & \multicolumn{2}{c}{ Poor Readers } \\
& $\mathrm{N}$ & $\%$ & $\mathrm{~N}$ & $\%$ \\
\hline Boys & 18 & 66.7 & 9 & 33.3 \\
Girls & 12 & 36.4 & 21 & 63.6 \\
\hline \hline
\end{tabular}

determine differences between good readers and poor readers in linguistic and cognitive skills, we performed independent t-tests followed by calculation of Cohen's $d$ as a measure of effect size. Lastly, we performed a bootstrapped forest analysis for the categorical outcome of reading with all the independent variables in the model. An alpha level of .05 was used for all the tests. Statistical analysis was performed with a computer program SPSS v.27 for Windows (IBM, 2020).

\section{RESULTS}

The first research question was to determine whether there are differences in the proportion of boys and girls in good and poor readers. These results are shown in Table I.

As can be from the Table I, the differences in the proportion of boys and girls seem to vary depending on the reading group. This was confirmed by $\chi 2$ test $(\chi 2=5.5 ; \mathrm{p}=$ 0.02 ) and Fisher's exact test (2-tail), $p=0.04$. More boys were in the category of good readers and more girls were in the category of poor readers.

We next performed independent t-tests between good readers and poor readers on mean values of linguistic and cognitive variables.

These results are shown in Table II.

TABLE II: MEAN DiFFERENCES BETWEEN GOOD AND POOR READERS ON LINGUISTIC AND COGNITIVE TASKS

\begin{tabular}{|c|c|c|c|c|c|c|c|}
\hline \multicolumn{2}{|c|}{ category } & \multirow{2}{*}{$\frac{\mathrm{N}}{30}$} & \multirow{2}{*}{$\begin{array}{l}\text { Mean } \\
68.67\end{array}$} & \multirow{2}{*}{$\begin{array}{c}\begin{array}{c}\text { Std. } \\
\text { Deviation }\end{array} \\
31.76\end{array}$} & \multirow{3}{*}{$\frac{\text { t-test }}{-0.8}$} & \multirow{3}{*}{$\frac{\mathrm{p}}{.42}$} & \multirow{3}{*}{$\begin{array}{c}\text { Cohen's } \\
-0.21\end{array}$} \\
\hline Rhyme detection & good & & & & & & \\
\hline time $^{a}$ & poor & 30 & 74.60 & 25.05 & & & \\
\hline \multirow{2}{*}{$\begin{array}{c}\text { Phoneme deletion } \\
\text { task }^{\mathrm{a}}\end{array}$} & good & 30 & 49.30 & 13.82 & \multirow{2}{*}{-5.3} & \multirow[b]{2}{*}{$<0.001$} & \multirow[b]{2}{*}{-1.4} \\
\hline & poor & 30 & 87.23 & 36.38 & & & \\
\hline \multirow{2}{*}{ RAN: Letters ${ }^{\mathrm{a}}$} & good & 30 & 24.47 & 5.10 & \multirow{2}{*}{-3.3} & \multirow{2}{*}{$<0.01$} & \multirow{2}{*}{-0.84} \\
\hline & poor & 30 & 29.27 & 6.23 & & & \\
\hline \multirow{2}{*}{ RAN: Object ${ }^{\mathrm{a}}$} & good & 30 & 44.87 & 6.64 & \multirow{2}{*}{-4.3} & \multirow{2}{*}{$<0.001$} & \multirow{2}{*}{-1.1} \\
\hline & poor & 30 & 55.37 & 11.65 & & & \\
\hline \multirow{2}{*}{$\begin{array}{c}\text { Corsi backwards } \\
\text { memory task }^{\mathrm{b}}\end{array}$} & good & 30 & 5.80 & 1.97 & \multirow{2}{*}{2.6} & \multirow{2}{*}{0.011} & \multirow{2}{*}{0.70} \\
\hline & poor & 30 & 4.33 & 2.32 & & & \\
\hline \multirow{2}{*}{ Processing speed ${ }^{\mathrm{c}}$} & good & 30 & 3236.41 & 499.52 & \multirow{2}{*}{-3.7} & \multirow{2}{*}{$<0.01$} & \multirow{2}{*}{-0.95} \\
\hline & poor & 30 & 3961.83 & 956.06 & & & \\
\hline \multirow{2}{*}{ Semantic fluency ${ }^{\mathrm{d}}$} & good & 30 & 16.63 & 4.51 & \multirow{2}{*}{2.1} & \multirow{2}{*}{0.04} & \multirow{2}{*}{0.54} \\
\hline & poor & 30 & 14.30 & 4.09 & & & \\
\hline
\end{tabular}

As can be seen from Table II, there were statistically significant differences between good readers and poor readers on almost all variables except for the rhyming abilities. The largest difference was on a phoneme deletion task, almost 1.5 SD in mean difference and smallest, statistically significant, difference was on semantic fluency task (1/2 of SD).

We next present results of bootstrapped forest analysis. Generalized R2 was .54 and misclassification rate was $11 \%$. Classification matrix is shown in Table III.

TABLE III: CLASSIFICATION MATRIX FOR PREDICTING GOOD AND POOR READERS

\begin{tabular}{ccc}
\hline \hline \multirow{2}{*}{ Actual category } & \multicolumn{2}{c}{ Predicted Count } \\
\cline { 2 - 3 } & poor & good \\
\hline poor & 24 & 6 \\
good & 1 & 29 \\
\hline \hline
\end{tabular}

Lastly, we present a variable contribution to the prediction power of the model to predict good and poor readers. These results are shown in Table IV.
TABLE IV: VARIABLE CONTRIBUTION TO DIFFERENTIATING GOOD AND POOR READERS

\begin{tabular}{ccc}
\hline DIFFERENTIATING GOOD AND POOR READERS \\
\hline Variable & $\mathrm{G}^{\wedge} 2$ & Portion \\
\hline phon_time & 5.22 & 0.2532 \\
PS_reaction & 4.54 & 0.2202 \\
RAN: Object & 3.47 & 0.1684 \\
Corsi_total & 2.21 & 0.1073 \\
RAN: letters & 1.93 & 0.0939 \\
SF & 1.92 & 0.0933 \\
\hline \hline
\end{tabular}

As can be seen from the table, the most important variable for differentiating good and poor readers was phoneme deletion task followed by processing speed. Rhyming speed had the smallest contribution to differentiating these two groups of readers.

\section{DISCUSSION}

The goal of the present paper was to determine differences in cognitive and linguistic skills of good and poor readers. An additional goal was to determine whether there are differences in proportion of boys and girls in good readers and poor readers. Results of this study have found that more boys were in the category of good readers and more girls in the category of poor readers, a finding that is in 
contrast with most of the current literature. There are a plethora of studies indicating that girls perform better at reading tasks than boys (Below et al., 2010; Logan \& Johnston, 2009; Nalipay et al., 2020). Explanations favoring girls' advantage in reading are positing motivational (Merisuo-Storm, 2006) and linguistic (Lundberg et al., 2012) factors to be main reasons on why the girls read better. This in turn leads girls to read more and thus increase the reading achievement gap. On the other hand, it is important to note that there are studies that found no differences in reading skills between boys and girls (Limbrick et al., 2012; White, 2007). In line with her study's results, White noted that the notion of boys' underachievement in reading is grossly overstated. Our results strongly support her claim.

There are several potential explanations on why we might have found boys advantage in reading. First, children in our sample did not come from a clinical sample of children with diagnosed reading disability. In fact, none of the students in the sample received additional special education or had the support of reading specialists. Thus, it might be the case that poor readers in this sample are different from children who have a diagnosis of dyslexia or some other reading disability that put boys at disadvantage. It is, of course, very likely that some children from our category of poor readers had in fact some unconfirmed form of reading disability. Secondly, it might be the case that the boys' attitudes towards reading are beginning to change and that the teachers are motivating boys to read more. Next explanation is relying on children's age, as children are on average eight years old. It might be the case that the differences in reading skills and different reading trajectory will begin to emerge later in schooling. Lastly, gender differences we found might have been sample specific and might have been achieved by chance, especially due to the small sample size. As this was an unexpected finding, more research with larger sample size is needed to examine this issue with more statistical power.

We next examined the differences on linguistic and cognitive variables between good and poor readers. Nonstatistically significant differences were found only on rhyming task. It is possible that children achieve ceiling level of functioning for this task at younger ages and that this task is not relevant predictor of reading skills at later age. Many studies indicate the importance of rhyming abilities in developing phonological awareness and reading skills (Bryant et al., 1990; Goswami, 1990; Riordan et al., 2018). It is probably the case that rhyming abilities are better predictors of good and poor readers at younger age and that its role in differentiating good and poor readers is reducing with child's increasing age and with schooling. At age of eight years it seems that rhyming task is not efficient for differentiating good and poor readers. Future studies should aim to determine the approximate age by which rhyming abilities can be useful in predicting reading development.

Second linguistic task in which we compared performance of good and poor readers was phoneme deletion task. On this task we found the largest mean difference between good readers and poor readers. Good readers, on average, achieved results that are 1.5 standard deviations better than poor readers' results. In fact, this was the single best predictor for differentiating good and poor readers. What is so special about phoneme deletion task? This task can be administered in several ways and formats (Gillam et al., 2011; Scholes, 1991; Stuart, 1990). One way is to have a list of words and the child is asked to read the words without the first, middle or last phoneme. This way of administering the task is dependent on the knowledge of alphabetic orthography and thus cannot be used with children who do not know letters. Second way to administer this task is to simply say a word to a child and then ask her to repeat the word without the first, middle, or last sound. Next, a child can be presented with a list of familiar objects and then asked to name the pictures without the first sound. This last task was the paradigm we used in this study. This task requires a child to use several cognitive, linguistic and perceptual processes in order to complete this task. On surface, this task appears to be a combination of classic phoneme deletion task and rapid naming task. In a study by Memisevic et al. (2020), authors found this task to be the best predictor of reading fluency. Given the data we obtained and the importance of this task it is surprising that this task in not more widely used in studies examining predictors of reading development.

In our study, both tasks RAN: Letters and RAN: Objects produced statistically significant mean differences between good readers and poor readers. According to the measure of effect size and variables contribution from bootstrapped forest model, RAN: Objects seem to be a better task than RAN: Letters in differentiating good and poor readers. Our findings are line with existing research regarding the importance of RAN in reading (Heikkilä et al., 2009; Memisevic et al., 2020; Papadopoulos et al., 2016; Wolff, 2014). RAN was found to independently, apart from phonemic awareness, affect reading development (Di Filippo et al., 2005).

Next task in which we examined differences between good and poor readers was working memory task, more specifically spatial working memory task. The effect size of the mean difference on this task between good and poor readers was large $(0.7 \mathrm{SD})$. Good readers have better spatial working memory than poor readers. Similar findings were found for verbal working memory tasks, with good readers having substantially better verbal working memory than poor readers (Hansen \& Bowey, 1994). Working memory and reading abilities seem to be related across the lifespan, with poor readers performing significantly lower than average readers (Siegel, 1994).

Good readers achieved significantly better results (around 1SD) than poor readers on processing speed task. Bootstrapped forest model identified processing speed task as the second most important variable in differentiating good and poor readers. Processing speed is related to general intelligence and some studies have found that increases in processing speed lead to increases in general intelligence (Coyle et al., 2011). Earlier studies have shown that processing speed is associated with academic achievement, with both reading (Shanahan et al., 2006) and math skills (Rohde \& Thompson, 2007).

Last variable that we examined in good and poor readers is semantic fluency. We found that good readers achieved better results than poor readers (around $1 / 2$ of $\mathrm{SD}$ ) in 
semantic fluency. Semantic fluency depends on educational level - the more education and more knowledge the better semantic fluency (Mathuranath et al., 2003). Impact of semantic fluency was second to last important predictor in differentiating good and poor readers. It might be the case, as the semantic category was animals, that most children achieved close to ceiling result and thus the difference is not a large one. If we instead used the more difficult semantic category (e.g. music instruments) the differences between good and poor readers might have been larger.

Knowing the factors that differentiate good and poor readers will help teachers employ more successful strategies in improving students' reading. It has been well established that teachers' role in reading instruction is of the utmost importance (Rupley, 2009). In this study none of the students in poor readers category received special education instruction or additional reading instruction. It is possible that teachers are referring only children with more significant disabilities (e.g. intellectual disability) to have special education and are not trained sufficiently to recognize and work with children who have reading difficulties. Thus, teachers in BIH need to be additionally trained to use effective, evidence-based, instruction methods and to know on what developmental areas to work in order to increase students reading abilities.

Let us finally mention several limitations in this study. First the sample size was rather small and possibly unrepresentative of the true population of good and poor readers. Second, the sample was drawn from third-grade students only and the impact of examined cognitive and linguistic factors in other grades might have been different. Lastly, the selection of good and poor readers was based only on two measures: fluency and comprehension, or more precisely comprehension measure adjusted for reading speed. More reading achievement tests would have increased the validity of the categories.

\section{CONCLUSION}

The most important variable for differentiating good and poor readers was phoneme deletion task followed by processing speed task. More boys than girls were in the category of good readers and more girls were in the category of poor readers. It is important to know what factors are affecting reading abilities at different ages and grades. This will help educators and reading specialists create better reading intervention programs.

\section{ACKNOWLEDGMENT}

This study was supported by the Canton Sarajevo Ministry of Education, Science and Youth.

\section{CONFLICT OF INTEREST}

The authors report no conflict of interest.

\section{REFERENCES}

Below, J. L., Skinner, C. H., Fearrington, J. Y., \& Sorrell, C. A. (2010). Gender Differences in Early Literacy: Analysis of Kindergarten through Fifth-Grade Dynamic Indicators of Basic Early Literacy Skills Probes. School Psychology Review, 39(2), 240-257. https://doi.org/10.1080/02796015.2010.12087776

Biščević, I., Maleč, D., \& Memišević, H. (2021). The Relationship of Reading and Mathematics in Third-Grade Elementary School Students in Canton Sarajevo. Školski vjesnik: časopis za pedagogijsku teoriju i praksu, 70(1), 207-226.

Breda, T., \& Napp, C. (2019). Girls' comparative advantage in reading can largely explain the gender gap in math-related fields. Proceedings of the National Academy of Sciences, 116(31), 15435-15440. https://doi.org/10.1073/pnas.1905779116

Bryant, P. E., MacLean, M., Bradley, L. L., \& Crossland, J. (1990). Rhyme and alliteration, phoneme detection, and learning to read. Developmental psychology, 26(3), 429-438.

Cain, K., Oakhill, J., \& Bryant, P. (2004). Children's Reading Comprehension Ability: Concurrent Prediction by Working Memory, Verbal Ability, and Component Skills. Journal of Educational Psychology, 96(1), 31-42. https://doi.org/10.1037/0022-0663.96.1.31

Carroll, J. M., \& Snowling, M. J. (2004). Language and phonological skills in children at high risk of reading difficulties. Journal of Child Psychology and Psychiatry, 45(3), 631-640.

Coyle, T. R., Pillow, D. R., Snyder, A. C., \& Kochunov, P. (2011). Processing Speed Mediates the Development of General Intelligence (g) in Adolescence. Psychological Science, 22(10), 1265-1269. https://doi.org/10.1177/0956797611418243

Crosson, A. C., \& Lesaux, N. K. (2010). Revisiting assumptions about the relationship of fluent reading to comprehension: Spanish-speakers' text-reading fluency in English. Reading and Writing, 23(5), 475-494. https://doi.org/10.1007/s11145-009-9168-8

Daly, M., \& Corcoran, R. P. (2019). Kindergarten self-control mediates the gender reading achievement gap: A population-based cohort study. Journal of Research in Personality, 83, 103881. https://doi.org/https://doi.org/10.1016/j.jrp.2019.103881

Di Filippo, G., Brizzolara, D., Chilosi, A., De Luca, M., Judica, A., Pecini, C., Spinelli, D., \& Zoccolotti, P. (2005). Rapid naming, not cancellation speed or articulation rate, predicts reading in an orthographically regular language (Italian). Child Neuropsychology, 11(4), 349-361. https://doi.org/10.1080/09297040490916947

Fluss, J., Ziegler, J., Ecalle, J., Magnan, A., Warszawski, J., Ducot, B., Richard, G., \& Billard, C. (2008). Prevalence of reading disabilities in early elementary school: impact of socioeconomic environment on reading development in 3 different educational zones. Archives de pediatrie : organe officiel de la Societe francaise de pediatrie, 15(6), 1049-1057. https://doi.org/10.1016/j.arcped.2008.02.012

Fuchs, L. S., Fuchs, D., Hosp, M. K., \& Jenkins, J. R. (2001). Oral reading fluency as an indicator of reading competence: A theoretical, empirical, and historical analysis. Scientific studies of reading, 5(3), 239-256.

Georgiou, G. K., Parrila, R., \& Papadopoulos, T. C. (2008). Predictors of word decoding and reading fluency across languages varying in orthographic consistency. Journal of Educational Psychology, 100(3), 566-580. https://doi.org/10.1037/0022-0663.100.3.566

Gillam, S. L., Fargo, J., Foley, B., \& Olszewski, A. (2011). A nonverbal phoneme deletion task administered in a dynamic assessment format. Journal of Communication Disorders, 44(2), 236-245. https://doi.org/https://doi.org/10.1016/j.jcomdis.2010.11.003

Goswami, U. (1990). A Special Link between Rhyming Skill and the Use of Orthographic Analogies by Beginning Readers. Journal of Child Psychology and Psychiatry, 31(2), 301-311. https://doi.org/https://doi.org/10.1111/j.1469-7610.1990.tb01568.x

Grigorenko, E. L., Klin, A., \& Volkmar, F. (2003). Annotation: Hyperlexia: disability or superability? Journal of Child Psychology and Psychiatry, 44(8), 1079-1091.

Hansen, J., \& Bowey, J. A. (1994). Phonological Analysis Skills, Verbal Working Memory, and Reading Ability in Second-Grade Children. Child Development, 65(3), 938-950. https://doi.org/10.1111/j.14678624.1994.tb00794.x

Hasbrouck, J., \& Tindal, G. A. (2006). Oral reading fluency norms: A valuable assessment tool for reading teachers. The Reading Teacher, 59(7), 636-644.

Heikkilä, R., Närhi, V., Aro, M., \& Ahonen, T. (2009). Rapid Automatized Naming and Learning Disabilities: Does RAN Have a Specific Connection to Reading or Not? Child Neuropsychology, 15(4), 343358. https://doi.org/10.1080/09297040802537653 
Hoover, W. A., \& Gough, P. B. (1990). The simple view of reading. $\begin{array}{lll}\text { Reading } \quad \text { and } & \text { Writing, } & \text { 127-160. }\end{array}$ https://doi.org/10.1007/bf00401799

Hoskyn, M., \& Swanson, H. L. (2000). Cognitive processing of low achievers and children with reading disabilities: A selective metaanalytic review of the published literature. School Psychology Review, 29(1), 102-119.

Kessels, R. P., Van Zandvoort, M. J., Postma, A., Kappelle, L. J., \& De Haan, E. H. (2000). The Corsi block-tapping task: standardization and normative data. Applied neuropsychology, 7(4), 252-258.

Landerl, K., Freudenthaler, H. H., Heene, M., De Jong, P. F., Desrochers, A., Manolitsis, G., Parrila, R., \& Georgiou, G. K. (2019). Phonological Awareness and Rapid Automatized Naming as Longitudinal Predictors of Reading in Five Alphabetic Orthographies with Varying Degrees of Consistency. Scientific Studies of Reading, 23(3), 220-234. https://doi.org/10.1080/10888438.2018.1510936

Limbrick, L., Wheldall, K., \& Madelaine, A. (2012). Reading and Related Skills in the Early School Years: Are boys really more likely to struggle? International Journal of Disability, Development and $\begin{array}{ll}\text { Education, } & \text { 59(4), }\end{array}$ https://doi.org/10.1080/1034912x.2012.723939

Logan, S., \& Johnston, R. (2009). Gender differences in reading ability and attitudes: examining where these differences lie. Journal of Research in Reading, 32(2), 199-214. https://doi.org/10.1111/j.14679817.2008.01389.x

Lundberg, I., Larsman, P., \& Strid, A. (2012). Development of phonological awareness during the preschool year: the influence of gender and socio-economic status. Reading and Writing, 25(2), 305320. https://doi.org/10.1007/s11145-010-9269-4

Mathuranath, P. S., George, A., Cherian, P. J., Alexander, A., Sarma, S. G., \& Sarma, P. S. (2003). Effects of Age, Education and Gender on Verbal Fluency. Journal of Clinical and Experimental $\begin{array}{lcr}\text { Neuropsychology, } & \text { 25(8), } & \text { 1057-1064. }\end{array}$ https://doi.org/10.1076/jcen.25.8.1057.16736

Memisevic, H., Dedic, A., Biscevic, I., Hadzic, S., Pasalic, A., \& Malec, D. (2020). Identifying predictors of reading speed and reading comprehension in Bosnian. Applied Neuropsychology: Child, 1-10. https://doi.org/10.1080/21622965.2020.1815023

Memisevic, H., Malec, D., Biscevic, I., \& Pasalic, A. (2019). Predictors of Reading Fluency in Second and Third Grade Students: Results from Bosnia and Herzegovina. Studia Psychologica, 61(3), 175-188.

Merisuo-Storm, T. (2006). Girls and Boys Like to Read and Write Different Texts. Scandinavian Journal of Educational Research, 50(2), 111125. https://doi.org/10.1080/00313830600576039

Morris, D., Pennell, A. M., Perney, J., \& Trathen, W. (2018). Using subjective and objective measures to predict level of reading fluency at the end of first grade. Reading Psychology, 39(3), 253-270. https://doi.org/10.1080/02702711.2017.1418466

Mueller, S. T., \& Piper, B. J. (2014). The psychology experiment building language (PEBL) and PEBL test battery. Journal of neuroscience methods, 222, 250-259.

Nalipay, M. J. N., Cai, Y., \& King, R. B. (2020). Why do girls do better in reading than boys? How parental emotional contagion explains gender differences in reading achievement. Psychology in the Schools, 57(2), 310-319. https://doi.org/10.1002/pits.22330

Ostrolenk, A., d'Arc, B. F., Jelenic, P., Samson, F., \& Mottron, L. (2017). Hyperlexia: Systematic review, neurocognitive modelling, and outcome. Neuroscience \& Biobehavioral Reviews, 79, 134-149.

Papadopoulos, T. C., Spanoudis, G. C., \& Georgiou, G. K. (2016). How Is RAN Related to Reading Fluency? A Comprehensive Examination of the Prominent Theoretical Accounts [Original Research]. Frontiers in Psychology, 7(1217). https://doi.org/10.3389/fpsyg.2016.01217

Park, Y., \& Kim, M. K. (2015). The quality of evidence in reading fluency intervention for Korean readers with reading difficulties and disabilities. Asia Pacific Education Review, 16(4), 637-651. https://doi.org/10.1007/s12564-015-9404-7

Pikulski, J. J., \& Chard, D. J. (2005). Fluency: Bridge Between Decoding and Reading Comprehension. The Reading Teacher, 58(6), 510-519. https://doi.org/10.1598/rt.58.6.2

Powell, D., Stainthorp, R., Stuart, M., Garwood, H., \& Quinlan, P. (2007). An experimental comparison between rival theories of rapid automatized naming performance and its relationship to reading. Journal of experimental child psychology, 98(1), 46-68.

Reilly, D., Neumann, D. L., \& Andrews, G. (2019). Gender differences in reading and writing achievement: Evidence from the National Assessment of Educational Progress (NAEP). American Psychologist, 74(4), 445-458. https://doi.org/10.1037/amp0000356

Riordan, J., Reese, E., Rouse, S., \& Schaughency, E. (2018). Promoting code-focused talk: The rhyme and reason for why book style matters.
Early Childhood Research Quarterly, 45, https://doi.org/https://doi.org/10.1016/j.ecresq.2018.05.004

Rohde, T. E., \& Thompson, L. A. (2007). Predicting academic achievement with cognitive ability. Intelligence, 35(1), 83-92. https://doi.org/https://doi.org/10.1016/j.intell.2006.05.004,

Romeo, R. R., Christodoulou, J. A., Halverson, K. K., Murtagh, J., Cyr, A. B., Schimmel, C., Chang, P., Hook, P. E., \& Gabrieli, J. D. E. (2017). Socioeconomic Status and Reading Disability: Neuroanatomy and Plasticity in Response to Intervention. Cerebral Cortex, 28(7), 2297 2312. https://doi.org/10.1093/cercor/bhx131

Rupley, W. H. (2009). Introduction to Direct/Explicit Instruction in Reading for the Struggling Reader: Phonemic Awareness, Phonics, Fluency, Vocabulary, and Comprehension. Reading \& Writing Quarterly, Quarterly, 25(2-3), https://doi.org/10.1080/10573560802690189

Scholes, R. J. (1991). Phoneme deletion and literacy in native and nonnative speakers of English. Journal of Research in Reading, 14(2), 130-140. https://doi.org/10.1111/j.1467-9817.1991.tb00014.x

Shanahan, M. A., Pennington, B. F., Yerys, B. E., Scott, A., Boada, R., Willcutt, E. G., Olson, R. K., \& DeFries, J. C. (2006). Processing Speed Deficits in Attention Deficit/Hyperactivity Disorder and Reading Disability. Journal of Abnormal Child Psychology, 34(5), 584. https://doi.org/10.1007/s10802-006-9037-8

Siegel, L. S. (1994). Working Memory and Reading: A Life-span Perspective. International Journal of Behavioral Development, 17(1), 109-124. https://doi.org/10.1177/016502549401700107

Stuart, M. (1990). Processing strategies in a phoneme deletion task. The Quarterly Journal of Experimental Psychology Section A, 42(2), 305327. https://doi.org/10.1080/14640749008401224

Tobia, V., \& Marzocchi, G. M. (2014). Predictors of reading fluency in Italian orthography: Evidence from a cross-sectional study of primary school students. Child Neuropsychology, 20(4), 449-469. https://doi.org/10.1080/09297049.2013.814768

Troyer, A. K., Moscovitch, M., \& Winocur, G. (1997). Clustering and switching as two components of verbal fluency: Evidence from younger and older healthy adults. Neuropsychology, 11(1), 138-146. https://doi.org/10.1037/0894-4105.11.1.138

Troyer, M., Kim, J. S., Hale, E., Wantchekon, K. A., \& Armstrong, C. (2019). Relations among intrinsic and extrinsic reading motivation, reading amount, and comprehension: a conceptual replication. Reading and Writing, 32(5), 1197-1218.

White, B. (2007). Are Girls Better Readers than Boys? Which Boys? Which Girls? Canadian Journal of Education / Revue canadienne de l'éducation, 30(2), 554-581. https://doi.org/10.2307/20466650

Wolf, M., \& Denckla, M. B. (2005). The rapid automatized naming and rapid alternating stimulus tests (RAN/RAS). Pro-ed.

Wolff, U. (2014). RAN as a predictor of reading skills, and vice versa: results from a randomised reading intervention. Annals of Dyslexia, 64(2), 151-165. https://doi.org/10.1007/s11881-014-0091-6

Zoccolotti, P., de Jong, P. F., \& Spinelli, D. (2016). Editorial: Understanding Developmental Dyslexia: Linking Perceptual and Cognitive Deficits to Reading Processes [Editorial]. Frontiers in Human Neuroscience, https://doi.org/10.3389/fnhum.2016.00140

Zumeta, R. O., Compton, D. L., \& Fuchs, L. S. (2012). Using Word Identification Fluency to Monitor First-Grade Reading Development. Exceptional Children, 78(2), 201-220. https://doi.org/10.1177/001440291207800204 